\title{
Are Japanese macaques threatened by neuroscience research?
}

TO THE EDITOR-Your recent editorial, "Primate research faces extinction," makes two points: that the Japanese macaque, Macaca fuscata, may be an endangered species, and that its use for research purposes by neuroscientists in Japan may be contributing to the danger of extinction. We disagree with both points.

There are two subspecies of Japanese macaques, $M$. fuscata fuscata, which is found on the Japanese mainland, and M. fuscata yakui, which is found only on the island of Yaku. There were 3,500 individuals of the yakui subspecies remaining in 1996, and the Japanese primatologists labeled this subspecies as being endangered. Presumably because of the scarcity of the yakui subspecies, the 1996 Red List of threatened species classified the Japanese macaque as endangered. In 1998, the Japanese Mammalogical Society agreed that the yakui subspecies was vulnerable, but also pointed out that the more common subspecies, M. fuscata fuscata, had a population of over 100,000 in the wild, and was at no risk. The Japanese macaque was excluded from the endangered classification of IUCN Red List in 2000, although it still remains on the list as 'data deficient.'

Despite the large numbers of wild $M$. fuscata fuscata in Japan, it is illegal to capture and use them solely for research purposes. However, farmers in Japan view these animals as agricultural pests, and request the local governments to remove them. Japanese researchers, including neuroscientists, use a small proportion of these captured monkeys as research subjects. Those not used for research are killed immediately under the supervision of local authorities.

Despite the availability of monkeys captured as agricultural pests, any wild population may be subject to change for unpredictable reasons. We therefore feel that there is an urgent need for the establishment of breeding colonies that would produce Japanese macaques for research purposes. Because it takes about seven years for newborn monkeys to become sexually mature breeders, however, we estimate that it will take a long time for breeding colonies to be able to supply an adequate number of research monkeys. At present it is crucial that agricultural pest monkeys continue to be made available to Japanese scientists for research.

\section{Kunihiko Obata \\ Japan N euroscience Society \\ Laboratory of Neurochemistry, National Institute for Physiological Sciences, M yodaiji, Okazaki 444-8585, Japan \\ email: obata@nips.ac.jp}

TO THE EDITOR-As primate biologists who advise the Species Survival Commission (SSC) of IUCN-The World Conservation Union (International Union for the Conservation of Nature and Natural Resources), we would like to clarify the status of the Japanese macaque, Macaca fuscata, which was discussed in your recent editorial ${ }^{1}$.

IUCN produces an ongoing updated list of threatened animal species, the socalled Red List, which was distributed electronically for the first time in 2000. On the preceding 1996 list, M. fuscata was categorized as endangered (EN) based on standardized criteria developed by IUCN (see www.redlist.org for details). For the 2000 list, the status of all primates was reviewed at the subspecific level. In anticipation of this, the IUCN/SSC Primate Specialist Group (PSG) helped to organize a workshop in February 2000, to document primate biodiversity and begin preparation of a comprehensive taxonomy of the primates. As is customary with Red List updates, an effort was made to obtain the most current information on the status of primate taxa from field primatologists in habitat (source) countries. For the Japanese macaque, the subspecies on Yaku Island (M. fuscata yakui or the Yakushima macaque) was adjudged to be endangered (EN) following criteria $\mathrm{B} 2 \mathrm{c}$ : the total natural range is less than $500 \mathrm{~km}^{2}$ and there is continuing decline in the quality of habitat. The numerically dominant subspecies $M$. fuscata fuscata proved to be difficult to evaluate. The monkeys' distribution has expanded over much of Honshu island; some local populations are declining, others are apparently expanding in range, but an absence of demographic data makes it impossible to know in most instances whether populations are increasing or decreasing.
The local population of Shimokita has doubled or even quadrupled, and distribution has expanded. In some cases, such as Mie prefecture, reported increases in numbers may be the consequence of growing dependence on human crops with abandonment of deep forest habitat. In this instance, most of the area is covered by conifer trees, whereas broadleaf forests are small and fragmented; home ranges are very large, about 10-30 $\mathrm{km}^{2}$. Many populations are living in extremely disturbed and fragmented habitats and/or are subject to heavy pressure from trapping and hunting, sometimes resulting in local extirpations, because of damage to crops. There are strong indications that the increased perception of primates as pests, and consequent attempts to control them, is rapidly becoming a serious threat to primate conservation in many areas worldwide, comparable to those posed by habitat loss and hunting. Because accurate data on M. fuscata fuscata population densities are few, the most appropriate category, both for this subspecies and for the species as a whole, would appear to be 'data deficient' (DD). This change of status is not to be construed as a response to protests to the 1996 listing by 'Japanese researchers,' contrary to the claim in your recent editorial ${ }^{1}$. One alternative to the DD designation would be to recognize the species as 'vulnerable' (VU) under criteria A2c, acknowledging continuing decline in occurrence and quality of habitat; another alternative would be to evaluate the status of the different regional populations, as $M$. fuscata fuscata does not seem to fit comfortably into the IUCN categories.

\section{Ardith A. Eudey1, David A. Hill ${ }^{2}$ and Yasuyuki Muroyama ${ }^{3}$ \\ 1 Vice chair for Asia, IUCN/SSC Primate Specialist Group, 164 Dayton Street, Upland, California 91786-3120, USA email: eudey@aol.com \\ 2 School of Biological Sciences, University of Sussex, Falmer, Brighton BN 1D 9QG, UK \\ 3 Field Research Center, Primate Research Institute Kyoto University, Inuyama, Aichi 484-8506, Japan}

1 . Primate research faces extinction. Nat. Neurosci. 4, 111 (2001). 